AperTO - Archivio Istituzionale Open Access dell'Università di Torino

\title{
Looking forward to genetically edited fruit crops
}

\section{This is the author's manuscript}

Original Citation:

Availability:

This version is available http://hdl.handle.net/2318/149940

since 2016-06-23T12:31:22Z

Published version:

DOI:10.1016/j.tibtech.2014.07.003

Terms of use:

Open Access

Anyone can freely access the full text of works made available as "Open Access". Works made available under a Creative Commons license can be used according to the terms and conditions of said license. Use of all other works requires consent of the right holder (author or publisher) if not exempted from copyright protection by the applicable law. 
This Accepted Author Manuscript (AAM) is copyrighted and published by Elsevier. It is posted here by agreement between Elsevier and the University of Turin. Changes resulting from the publishing process - such as editing, corrections, structural formatting, and other quality control mechanisms - may not be reflected in this version of the text. The definitive version of the text was subsequently published in TRENDS IN BIOTECHNOLOGY, 33, 2015, 10.1016/j.tibtech.2014.07.003.

You may download, copy and otherwise use the AAM for non-commercial purposes provided that your license is limited by the following restrictions:

(1) You may use this AAM for non-commercial purposes only under the terms of the CC-BY-NC-ND license.

(2) The integrity of the work and identification of the author, copyright owner, and publisher must be preserved in any copy.

(3) You must attribute this AAM in the following format: Creative Commons BY-NC-ND license (http://creativecommons.org/licenses/by-nc-nd/4.0/deed.en), 10.1016/j.tibtech.2014.07.003

The publisher's version is available at:

http://linkinghub.elsevier.com/retrieve/pii/S0167779914001474

When citing, please refer to the published version.

Link to this full text:

http://hdl.handle.net/2318/149940 


\section{Looking forward: genetically edited fruit crops}

Chidananda Nagamangala Kanchiswamy ${ }^{1 *}$, Daniel James Sargent ${ }^{1}$, Riccardo Velasco ${ }^{1}$, Massimo E. Maffei ${ }^{2}$, Mickael Malnoy ${ }^{1}$

${ }^{1}$ Research and Innovation Centre Genomics and Biology of Fruit Crop Department, Fondazione Edmund Mach (FEM), Istituto Agrario San Michele (IASMA), Via Mach 1, 38010 San Michele all'Adige (TN), Italy;

${ }^{2}$ Department of Life Sciences and Systems Biology, Innovation Centre, University of Turin, Via Quarello 15/A, 10135 Turin, Italy;

The availability of genome sequences for many fruit crops has redefined the boundaries of genetic engineering and genetically modified crop plants (GM crops). However commercialization of GM crops are hindered by numerous regulatory and social hurdles. Here we focus on recently developed genome editing tools for fruit crop improvement and their importance from the consumer perspective. Challenges and opportunities for the deployment of new genome editing tools for fruit plants are also discussed.

\section{Background}

Fruits are a major source of fiber, nutrients, and antioxidants, all essential for a healthy diet. Fruit crops play a key role in the economy of both developed and developing countries, and as such, efforts have been made to improve the quality of these crops using both conventional breeding and genetic engineering, which emerged as a major tool for introducing desirable genes in fruit crops. However, societal distrust for such technologies, coupled with misleading and false information regarding their safety, means that traditional genetically modified (GM) technology has been difficult, or impossible to commercialize successfully. For the past two decades, genetic transformation of fruit crops has mainly focused on the enhancement of biotic and abiotic tolerance; however, there are few cases of field evaluation and commercialization of these transgenic plants worldwide. 


\section{Commercialization of genetically modified fruit crop plants}

Public survey conducted by the European Union Eurobarometer concludes an ambiguous response of public respondents on accepting or buying GM foods. People shows more preference on GM foods if they are eco-friendly, free from pesticide residues and have more flavor, tasty and with low fat content [1]. Academic researchers or biotechnology industries should achieve minimum requirements of consumer preference on GM foods which helps consumers to find compelling reasons to buy GM foods [2]. GM papaya (Carica papaya L.) resistant to papaya ringspot virus (PRSV), has been cultivated for human consumption in the United States for more than a decade [3], and transgenic bananas (Musa acuminata) constitutively expressing the Hypersensitive Response Assisting Protein (Hrap) or Plant Ferredoxin Like Protein (Pflp) gene from sweet pepper (Capsicum annuиm) have been produced to combat banana Xanthomonas wilt (BXW), caused by Xanthomonas campestris pv. musacearum [4].

However, since fruit crops are not staple foods, there is more scope for marketing novel GM varieties, developed with novel technologies that enhance the consumer experience (e.g., with increased levels of antioxidants, better flavor, or sweetness) in addition to improvements such as pest and disease resistance. Where biotechnology is used to target the luxury product market, it has gained consumer acceptance. Examples include the 'blue' pigmented roses developed jointly in Japan and Australia using a transgene for the expression of the blue pigment delphinidin.

Combining the increased knowledge of the genomes of a range of fruit crops with novel DNA editing technologies will produce new fruit crop varieties with a range of novel traits. Such varieties could confer increased expression of desirable aromatics or sweetness, as well as contributing to a more sustainable mode of cultivation, such as pest and disease resistant phenotypes. Thus, there is scope within the market to offer the consumer a choice of products, including GM products, which offer environmental and societal benefits, as well as novelty and enhanced quality, thus enriching the quality of the consumer experience.

\section{Addressing current challenges}

The recent development of cost-effective high-throughput sequencing technologies has resulted in a significant increase in the availability of genomic information for fruit crop species. Recently the genomes of many fruit species have been published [5], paving the way for an 
improved understanding of many important crop traits including timing of flowering, control of juvenility, ripening, shelf life, and many others. Considering the regulatory and social hurdles associated with transgenic crops, novel biotechnological tools such as Zinc Finger Nuclease (ZFNs), transcription activator-like effector nucleases (TALENs) and clustered regulatory interspaced short palindromic repeat (CRISPRs)/Cas-based RNA-guided DNA endonucleases have emerged, allowing the precise insertion of specific genes for modification or replacement of genes at their specific genomic location without involving any other source of DNA. The absence of foreign DNA, most notably selectable markers in the final product, and the introduction of genes derived from the same plant species, should help to increase consumer acceptance of novel GM plant products developed with these technologies. Thus, with the emergence of such technologies, the time is right to revisit the benefits of genetic modification and to begin the development of novel, consumer-acceptable products. However, to date these novel biotechnological tools have been successfully demonstrated only in Arabiopsis, tobacco, rice, sorghum and Brachipodium [6-8].

\section{Novel biotechnological tools opportunities and technical barriers for fruit crop improvement.}

Conventional fruit crop breeding is a lengthy process. With the development of marker-assisted breeding, breeding time-scales have been reduced but still not significantly enough. However, the advent of new genome editing tools makes now possible to manipulate the plant genome with unprecedented control.

Engineered nucleases such as ZFNs and TALENs generate double-strand DNA breaks at almost any specific genomic location within plant, animal and human genome, allowing precise genome editing $[6,7]$. The latest development in the genome editing toolbox is the CRISPRs method, which is considered to be most efficient, cheaper and user friendly among the three genome editing tools [8]. Despite their innovation, these new technologies present technical barriers. ZFNs have problems with the efficiency and accuracy on site directed mutagenesis and insertion. TALENs offers more flexible, precision and cost effective system; however, until recently both ZFNs and TALENs methods have proven laborious and cumbersome in their design. As a result, these methods have not been widely adopted by plant research community. In 2012-13, a new CRISPRs method based on bacterial form of adoptive immune system has emerged and made 
tremendous progress in the research community. That is because CRISPRs system offers numerous advantages over ZFNs and TALENs: it is simple, inexpensive, easy to design and extremely efficient. A major drawback of these genome-editing tools including CRISPRs are target specificity and accuracy. Detailed methods and limitations of genome editing tools have been described in a number of recent articles [9-11], and a number of recent scientific reports on CRISPRs target specificity suggest ambiguous conclusions. Reports show controversial evidence of off target using CRISPRs [12-14], therefore, comprehensive studies and caution are required to draw any conclusion on these novel genome-editing tools before their use for fruit crop breeding can be accepted.

\section{Regulating genome edited fruit crops}

Many regulatory authorities are implementing new regulations to handle genome edited crop plants. Until now most regulations were limited to transgenic plants and most of the countries adopt either process or product based regulations (Box1).

ZFNs genome editing tools were considered worldwide by many countries to develop new regulations. Argentinian regulatory framework excludes ZFNs-1 from GM regulation, ZFNs-2 would be considered on a case by case basis and ZFNs-3 will be under product- and processbased regulation. EU regulatory bodies concluded that ZFNs-3 allows genes of interest to be delivered to predefined genomic positions unlike transgenesis and might be considered under EC regulations. Australian and New Zealand regulatory bodies concluded that ZFNs-1 and ZFNs-2 would be excluded but ZFNs-3 would be regulated. USA regulatory bodies consider possible exception of ZFNs-1 from regulation [11]. Other genome editing tools such as TALENs and CRISPRs are recently developed and hence regulation has yet to be defined.

\section{A chance for fruit biotechnology}

To date, ZFNs, TALENs and CRISPRs editing tools have not been applied to the genetic modification of fruit crops. Most transgenic fruit crop plants have been developed using Agrobacterium-mediated transformation, and amongst those that have been developed, only papaya has been commercialized. Existing EU regulation on GM organisms may consider the plants produced by ZFNs, TALENs and CRISPRs as non-GM depending on the interpretation of the EU commission and member state regulators [15]. The public awareness of the absence of 
"foreign gene" introduction perceived by the consumer, along with the effort to explain the advantages of using these new "friendly" genetic editing tools by central authorities, might reverse the actual dichotomy between European and US perception of GM biotechnology. Furthermore, the definition as non-GM foods would open to new scientific opinions and commercial opportunities for fruit crop improvement. This signifies the importance of these technologies for fruit crop plants welfare to ease any regulatory procedure for GM commercialization (Figure 1).

\section{Conclusions and future perspectives}

Recent genome editing tools by site-specific insertion, deletion or mutation of genes of interest are poised to have a significant effect on plant biotechnology. These tools permit the modification or mutation of genes of interest without involving foreign DNA, and as a result, plants developed with this technology might be considered as non-transgenic genetically altered plants. This would open the door for the development of fruit crops with superior phenotypes and permit their commercialization even in countries where GM crops are poorly accepted. Examples of such superior phenotype of fruit crops are genetically engineered 'super banana' which produces more vitamin A and non-browning apple which doesn't get brown after fresh cut and retains all its natural flavor, taste unlike other non-GM apple fruits [16, 17]. Acceptance of a new technology is not the issue; consumers experienced in the last 50 years the benefits of conventional breeding based on biotechnological tools. However, the growing food needs cannot be sustained by traditional breeding. These technologies have the potential to offer the consumer products that would be difficult, or impossible to produce using traditional breeding methods, without the addition of foreign DNA typical of traditional GM, that still generates strong consumer concerns and objections. These new crop fruits will remain biotech crops, which is largely acceptable. We suggest the name of Genetically Edited (GE) Crops for plants created with gene editing tools such as ZFNs, TALENs and CRISPRs.

\section{Acknowledgement}

This work was supported by research funding office Autonomous province of Trento. Authors would like to apologize colleagues whose work could not be cited owing to space limitations. 


\section{References}

1. $\quad$ 58.0 E: Europeans and Biotechnology http://wwwkeinegentechnikde/bibliothek/basis/studien/eurobaromenter europeans biotechnology 010303pdf 2002.

2. Biotechnology Ea: Eurobarometer. http://eceuropaeu/public opinion/archives/ebs/ebs 244b sum enpdf 2005.

3. Azad MA, Amin L, Sidik NM: Gene technology for papaya ringspot virus disease management. TheScientificWorldJournal 2014, 2014:768038.

4. Namukwaya B, Tripathi L, Tripathi JN, Arinaitwe G, Mukasa SB, Tushemereirwe WK: Transgenic banana expressing Pflp gene confers enhanced resistance to Xanthomonas wilt disease. Transgenic research 2012, 21(4):855-865.

5. Bolger ME, Weisshaar B, Scholz U, Stein N, Usadel B, Mayer KF: Plant genome sequencing applications for crop improvement. Current opinion in biotechnology 2014, 26C:31-37.

6. Townsend JA, Wright DA, Winfrey RJ, Fu F, Maeder ML, Joung JK, Voytas DF: High-frequency modification of plant genes using engineered zinc-finger nucleases. Nature 2009, 459(7245):442-445.

7. Shan Q, Wang Y, Chen K, Liang Z, Li J, Zhang Y, Zhang K, Liu J, Voytas DF, Zheng X et al: Rapid and efficient gene modification in rice and Brachypodium using TALENs. Molecular plant 2013, 6(4):1365-1368.

8. Jiang W, Zhou H, Bi H, Fromm M, Yang B, Weeks DP: Demonstration of CRISPR/Cas9/sgRNAmediated targeted gene modification in Arabidopsis, tobacco, sorghum and rice. Nucleic acids research 2013, 41(20):e188.

9. Gaj T, Gersbach CA, Barbas CF, 3rd: ZFNs, TALEN, and CRISPR/Cas-based methods for genome engineering. Trends in biotechnology 2013, 31(7):397-405.

10. Liu W, Yuan JS, Stewart CN, Jr.: Advanced genetic tools for plant biotechnology. Nature reviews Genetics 2013.

11. Araki M, Nojima K, Ishii T: Caution required for handling genome editing technology. Trends in biotechnology 2014, 32(5):234-237.

12. Shan Q, Wang Y, Li J, Zhang Y, Chen K, Liang Z, Zhang K, Liu J, Xi JJ, Qiu JL et al: Targeted genome modification of crop plants using a CRISPR-Cas system. Nature biotechnology 2013, 31(8):686688.

13. Xie K, Yang Y: RNA-guided genome editing in plants using a CRISPR-Cas system. Molecular plant 2013, 6(6):1975-1983.

14. Nekrasov V, Staskawicz B, Weigel D, Jones JD, Kamoun S: Targeted mutagenesis in the model plant Nicotiana benthamiana using Cas9 RNA-guided endonuclease. Nature biotechnology 2013, 31(8):691-693.

15. Pollock CJ, Hails RS: The case for reforming the EU regulatory system for GMOs. Trends in biotechnology 2014, 32(2):63-64.

16. banana S: Genetically engineered super banana. http://wwwdailymailcouk/sciencetech/article2660138/Super-bananas-sale-2020-Fruit-laced-vitamin-A-begins-humans-trials-tackledeficiency-Africahtml 2014.

17. apple N-b: http://wwwokspecialtyfruitscom/arctic-apples/browning-and-nonbrowning-science.

18. Rai M, Shekhawat NS: Recent advances in genetic engineering for improvement of fruit crops. Plant Cell Tiss Organ Cult 2014, 116(1):1-15. 


\section{Legend for Figure}

Figure 1. Comparison between GM technologies. Introduction of foreign DNA is the most spread technology applied to creations of GM organisms. Although generally accepted in some countries, this technology is hardly accepted in Europe. On the other hand, new emerging technologies such as ZFNs, TALENs and CRISPRs do not require insertion of foreign DNA, therefore they create less hurdles to public acceptance. The picture represents fruits for which gene have already been modified to fight biotic and abiotic stress [18].

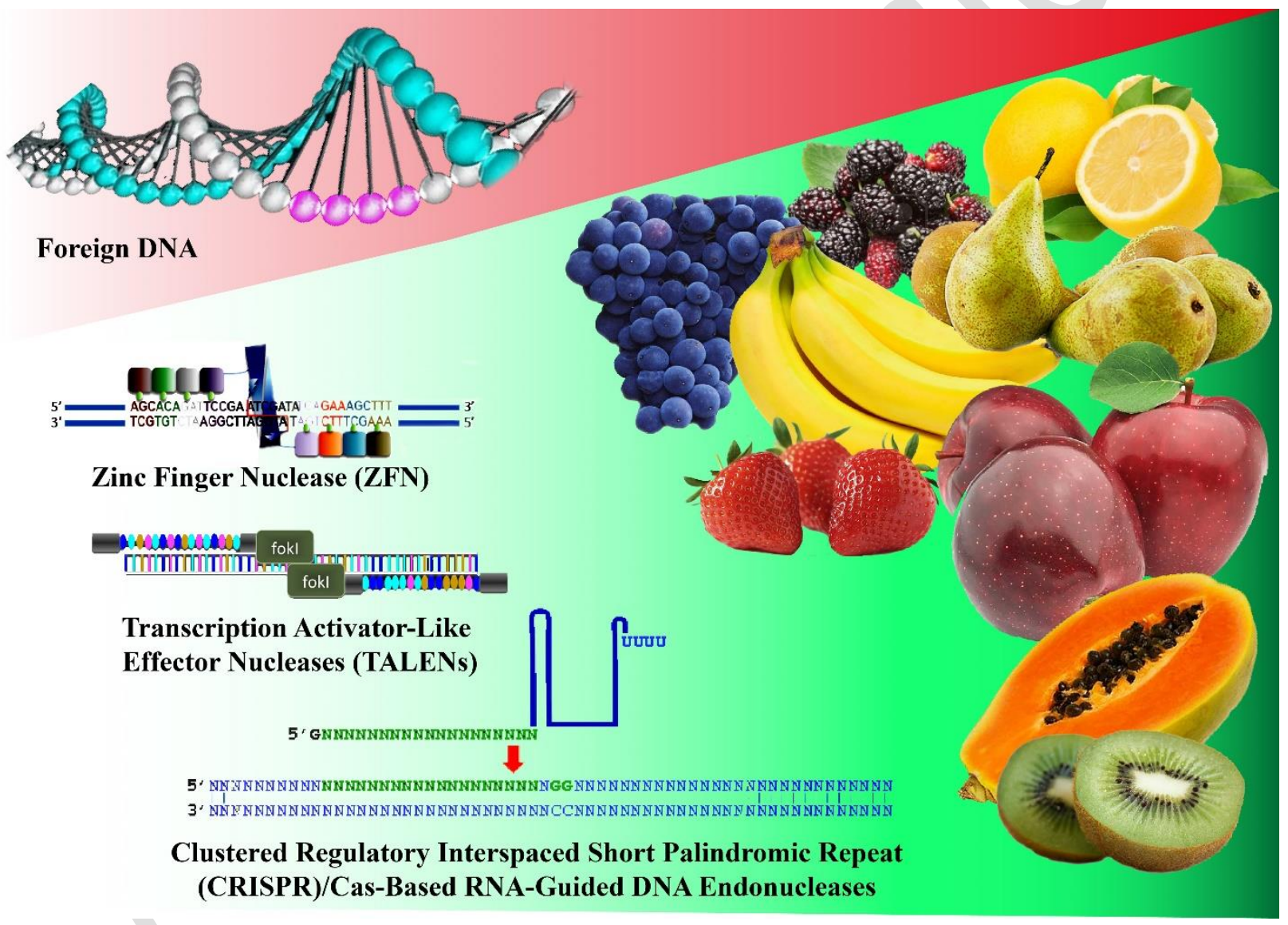

\section{Box 1. Regulatory process for GMO}

\section{Process based regulatory bodies}

In this regulatory framework, techniques or methods used to obtain GM plants are considered. For instance, if nucleic acid or recombinant DNA are introduced into the plant then this regulation will be 
implemented. This framework is followed by EU, Argentina, Brazil and few other countries. Guidelines for regulations are defined by United Nations Food and Agricultural Organization and treaties such as Cartragena protocol.

\section{Product based regulatory bodies}

In this regulatory framework, consideration will be more on the final product of GM plant. Risk assessment of the product on human health and environment is considered. This framework is followed by US and Canada. 